\title{
Early predictors of poor outcome after out-of-hospital cardiac arrest
}

\author{
Louise Martinell ${ }^{* *}$ (D), Niklas Nielsen², Johan Herlitz ${ }^{3}$, Thomas Karlsson ${ }^{4}$, Janneke Horn ${ }^{5}$, Matt P. Wise ${ }^{6}$, \\ Johan Undén ${ }^{7}$ and Christian Rylander ${ }^{1}$
}

\begin{abstract}
Background: Early identification of predictors for a poor long-term outcome in patients who survive the initial phase of out-of-hospital cardiac arrest (OHCA) may facilitate future clinical research, the process of care and information provided to relatives. The aim of this study was to determine the association between variables available from the patient's history and status at intensive care admission with outcome in unconscious survivors of OHCA.

Methods: Using the cohort of the Target Temperature Management trial, we performed a post hoc analysis of 933 unconscious patients with OHCA of presumed cardiac cause who had a complete 6-month follow-up. Outcomes were survival and neurological function as defined by the Cerebral Performance Category (CPC) scale at 6 months after OHCA. After multiple imputations to compensate for missing data, backward stepwise multivariable logistic regression was applied to identify factors independently predictive of a poor outcome (CPC 3-5). On the basis of these factors, a risk score for poor outcome was constructed.
\end{abstract}

Results: We identified ten independent predictors of a poor outcome: older age, cardiac arrest occurring at home, initial rhythm other than ventricular fibrillation/tachycardia, longer duration of no flow, longer duration of low flow, administration of adrenaline, bilateral absence of corneal and pupillary reflexes, Glasgow Coma Scale motor response 1, lower $\mathrm{pH}$ and a partial pressure of carbon dioxide in arterial blood value lower than $4.5 \mathrm{kPa}$ at hospital admission. A risk score based on the impact of each of these variables in the model yielded a median (range) AUC of 0.842 (0.840-0.845) and good calibration. Internal validation of the score using bootstrapping yielded a median (range) AUC corrected for optimism of $0.818(0.816-0.821)$.

Conclusions: Among variables available at admission to intensive care, we identified ten independent predictors of a poor outcome at 6 months for initial survivors of OHCA. They reflected pre-hospital circumstances (six variables) and patient status on hospital admission (four variables). By using a simple and easy-to-use risk scoring system based on these variables, patients at high risk for a poor outcome after OHCA may be identified early.

Keywords: Out-of-hospital cardiac arrest, Intensive care, Prognosis, Risk score

\section{Background}

For patients who are unconscious after out-of-hospital cardiac arrest (OHCA) and treated with hypothermia, survival rates around $50 \%$ are reported $[1,2]$. Prehospital factors such as time from collapse to start of cardiopulmonary resuscitation (CPR), time from collapse to return of spontaneous circulation (ROSC), initial rhythm, bystander CPR and lactate levels all are strongly

\footnotetext{
* Correspondence: louise.martinell@vgregion.se

1Department of Anaesthesiology and Intensive Care Medicine, Institute of Clinical Sciences, Sahlgrenska Academy, University of Gothenburg, SE-413 45 Gothenburg, Sweden

Full list of author information is available at the end of the article
}

correlated with outcome at a group level [2-7]. However, these correlations are based on large retrospective cohorts with no control for differences in patient treatment and may therefore be subject to bias. Furthermore, single predictors may not be reliable in individual cases, owing to difficulties in obtaining or recording precise information during pre-hospital management of cardiac arrest (CA) $[8,9]$. Currently, neurological prognostication in patients remaining unconscious is not recommended earlier than $72 \mathrm{~h}$ after the CA [10]. Nevertheless, in the OHCA patient population, with its elevated mortality, an earlier prediction of poor outcome is desirable for the 
process of care and information provided to the patient's relatives. An assessment of the risk for a poor outcome would also be of great value for comparing populations and to define patient risk when assessing effects in interventional studies. Efforts to construct a prediction score based on the set of data available at hospital admission have yielded the OHCA score [11] and the Cardiac Arrest Hospital Prognosis (CAHP) score [12]. When applied prospectively, the OHCA score showed moderate predictive accuracy [13]; however, none of these scores has been validated for clinical use.

The aim of this study was to establish a clinically useful association between parameters available from patient history and status at intensive care admission and outcome in comatose survivors of OHCA. The first step in the analysis was directed at determining the association between these factors and poor outcome at 6 months, defined as Cerebral Performance Category (CPC) 3-5 [14]. The second step was directed at constructing an easy-to-use risk score for prediction of a poor outcome.

\section{Methods}

We performed a post hoc analysis of data obtained in the Target Temperature Management (TTM) trial [15], in which researchers recruited patients from 36 intensive care units (ICUs) in Europe and Australia. The trial included adult patients ( $\geq 18$ years) resuscitated from OHCA of a presumed cardiac cause who remained unconscious (Glasgow Coma Scale [GCS] score $\leq 8$ ) more than 20 minutes after ROSC. The main exclusion criteria were unwitnessed asystole as the initial rhythm and refractory shock at hospital admission defined as sustained systolic blood pressure less than $80 \mathrm{mmHg}$ despite administration of fluids, vasopressors, inotropes and/or treatment with an intra-aortic balloon pump or left ventricular assist device [16].

Pre-hospital data, including initial rhythm, witnessed arrest, administration of bystander CPR and time from collapse to ROSC, were systematically collected at admission according to the Utstein guidelines [17]. Time from CA to initiation of basic life support (BLS; administered by bystanders or first responders) and advanced life support (ALS) was recorded. No-flow and low-flow times were defined as the time from CA to the start of CPR (BLS or ALS) and the time from the start of CPR to ROSC, respectively. Time to ROSC was defined as the time from CA to the first recorded time point of sustained spontaneous circulation. Patients were included in the present analysis if their CPC was recorded at follow-up 6 months after CA. All sites participating in the TTM trial registered patient data in a common electronic case report form. The process was monitored at each site by external reviewers who visited the centres and verified the correctness of registered data. All the centres used the same study protocol that defined target temperature management over time and prompted multimodal investigations for neurological prognostication. The results of the main trial were subjected to sensitivity analyses for time, study centre and other possible biases, all of which turned out negative.

The TTM trial demonstrated no difference in mortality and neurological outcome between a target temperature of $33^{\circ} \mathrm{C}$ and $36{ }^{\circ} \mathrm{C}$. The result has been further elaborated in post hoc analyses and sub-studies, which have so far shown similar outcomes in the two target temperature groups [18-21]. Therefore, data were pooled for the present analysis.

\section{Statistical analysis}

A description of original data is given in Tables 1, 2 and 3 , where categorical variables are presented as crude numbers and percentages and continuous variables are presented as medians with 25th and 75th percentiles. Logistic regression was used to calculate age-adjusted ORs with corresponding 95\% CIs and $p$ values. Continuous variables not fulfilling the linearity assumption were transformed using either natural logarithm or square root transformation.

Owing to the amount of missing data for several of the variables, multiple imputation was used for the multivariable analysis. Missing data were assumed to be missing at random $(p<0.01$ for Little's test of missing completely at random), and 50 imputed datasets were generated with the Markov chain Monte Carlo method and using the expectation-maximisation algorithm. Rubin's rules were used when pooling the results from the imputed datasets.

To identify independent predictors of a poor outcome, we started with a full model including all variables in Tables 1, 2 and 3. We excluded some continuous variables from the statistical analysis because of collinearity: CABLS time, CA-ALS time, CA-ROSC time, lactate, blood glucose and base excess on arrival to the hospital, as well as the dichotomous variables, intravenous drug abuse, immunodeficiency, cirrhosis and AIDS, that were present in fewer than five cases. Multiple logistic regression was performed in each of the 50 imputed datasets, and the variable with the highest $p$ value in the pooled result was excluded from the model. A new regression analysis was then performed in each imputed dataset, and of the remaining variables, the one with the highest $p$ value in the pooled result was excluded. This procedure was repeated until all remaining variables yielded a $p$ value below 0.01 in the pooled result. These variables were then used to develop our prognostic risk score (TTM risk score). To facilitate clinical use of the model, we used an approach similar to that adopted in the development of 
Table 1 Patient characteristics in relation to outcome

\begin{tabular}{|c|c|c|c|c|}
\hline & \multicolumn{2}{|c|}{ Outcome at 6 months } & \multicolumn{2}{|l|}{ Adjusted for age $\mathrm{e}^{\mathrm{a}}$} \\
\hline & $\overline{C P C} 1-2(n=440)$ & CPC 3-5 $(n=493)$ & OR $(95 \% \mathrm{Cl})^{\mathrm{b}}$ & $p$ Value \\
\hline Age, years & $61(52-69)$ & $68(61-76)$ & $1.06(1.05-1.07)$ & $<0.0001$ \\
\hline Female sex & $66(15)$ & $111(23)$ & $1.69(1.18-2.43)$ & 0.004 \\
\hline BMI $(5 / 20)^{c}$ & $25.3(23.4-27.8)$ & $26.1(23.9-29.4)$ & $1.05(1.01-1.08)$ & 0.006 \\
\hline Alcoholism (0/2) & $10(2)$ & $26(5)$ & $3.12(1.45-6.71)$ & 0.004 \\
\hline COPD/asthma (0/1) & $31(7)$ & $65(13)$ & $1.62(1.01-2.58)$ & 0.04 \\
\hline Previous heart failure $(0 / 3)$ & $16(4)$ & $44(9)$ & $1.75(0.95-3.22)$ & 0.07 \\
\hline Diabetes (2/4) & $51(12)$ & $89(18)$ & $1.41(0.96-2.08)$ & 0.08 \\
\hline CABG (0/4) & $26(6)$ & $62(13)$ & $1.49(0.90-2.44)$ & 0.12 \\
\hline TIA/stroke (1/3) & $23(5)$ & $50(10)$ & $1.51(0.89-2.57)$ & 0.13 \\
\hline Malignancy (3/4) & $9(2)$ & $22(4)$ & $1.89(0.82-4.35)$ & 0.13 \\
\hline Epilepsy (1/1) & $11(3)$ & $5(1)$ & $0.46(0.15-1.47)$ & 0.19 \\
\hline Arrhythmia (0/2) & $60(14)$ & $103(21)$ & $1.26(0.87-1.83)$ & 0.21 \\
\hline $\operatorname{ICD}(3 / 1)$ & $1(<1)$ & $4(<1)$ & $3.77(0.40-35.44)$ & 0.25 \\
\hline Hypertension (1/3) & $150(34)$ & $222(45)$ & $1.15(0.86-1.52)$ & 0.35 \\
\hline Dialysis (0/1) & $2(<1)$ & $4(<1)$ & $1.78(0.32-10.10)$ & 0.51 \\
\hline IHD (1/2) & $101(23)$ & $157(32)$ & $1.10(0.80-1.50)$ & 0.57 \\
\hline Intravenous drug abuse (2/1) & $2(<1)$ & $2(<1)$ & $1.67(0.21-13.04)$ & 0.63 \\
\hline Pacemaker (2/2) & $11(3)$ & $21(4)$ & $1.17(0.54-2.52)$ & 0.68 \\
\hline Cardiac valve surgery $(1 / 4)$ & $10(2)$ & $15(3)$ & $1.17(0.50-2.73)$ & 0.71 \\
\hline $\mathrm{PCl}(0 / 4)$ & $45(10)$ & $62(13)$ & $1.08(0.70-1.65)$ & 0.73 \\
\hline Previous cardiac arrest (0/2) & $9(2)$ & $12(2)$ & $1.13(0.44-2.91)$ & 0.79 \\
\hline Immunodeficiency (2/1) & $2(<1)$ & $2(<1)$ & $1.16(0.14-9.25)$ & 0.89 \\
\hline Previous AMI (0/2) & $79(18)$ & $112(23)$ & $0.99(0.70-1.39)$ & 0.94 \\
\hline Cirrhosis (0/1) & $0(0)$ & $3(<1)$ & & \\
\hline AIDS (4/4) & $1(<1)$ & $0(0)$ & & \\
\hline
\end{tabular}

Abbreviations: CPC Cerebral Performance Category, BMI Body mass index, COPD Chronic obstructive pulmonary disease, CABG Coronary artery bypass grafting, TIA Transient ischaemic attack, ICD Implantable cardioverter defibrillator, IHD Intermittent haemodialysis, $P C I$ Percutaneous coronary intervention, $A M I$ Acute myocardial infarction, AIDS Acquired immune deficiency syndrome, immunodeficiency other than AIDS

Data are presented as number (\%) or median (25th and 75 th percentiles)

Poor outcome was defined as CPC 3-5 at 6 months

${ }^{a}$ Except for age itself

${ }^{b} \mathrm{OR}$ for poor outcome (CPC 3-5) with corresponding $95 \% \mathrm{Cl}$

${ }^{\mathrm{C}}$ Number missing in the two groups, respectively

the Framingham Risk Score [22]. We let the increase in risk associated with a 5 -year increase in age, reflected by five times the $\beta$-coefficient for age in the final model, correspond to 1 point. We then determined points associated with each of the other categories of the identified risk factors by how far in regression units each category was from the corresponding factor's base category (i.e., when points $=0$ ), dividing that distance by five times the $\beta$-coefficient for age and rounding to the nearest integer.

The AUC was used to evaluate discrimination and the concordance percentage, and the Hosmer-Lemeshow goodness-of-fit test was used to evaluate calibration. This was done for all 50 imputed datasets, and the median and range of these are presented. The first five imputed datasets were used to calculate predicted versus observed risk as well as sensitivity, specificity, and positive and negative predicted values. Youden's J statistic was used to select the optimum cut-off of the score. Internal validation was also performed in the first five imputed datasets using bootstrapping (1000 resamples in each set), and the maximum of these was used as an estimate of optimism. No external validation was performed.

Two-sided tests were used, and $p$ values below 0.01 were considered statistically significant. All analyses were performed using SAS version 9.3 for Windows software (SAS Institute, Cary, NC, USA), except for Little's test, for which IBM SPSS Statistics version 23 software (IBM, Armonk, NY, USA) was used. 
Table 2 Circumstantial factors

\begin{tabular}{|c|c|c|c|c|}
\hline & Outcome at 6 mon & & Adjusted for age & \\
\hline & CPC 1-2 $(n=440)$ & CPC 3-5 $(n=493)$ & $\mathrm{OR}(95 \% \mathrm{Cl})^{\mathrm{a}}$ & $p$ Value \\
\hline CA at home $(0 / 1)^{b}$ & $192(44)$ & $306(62)$ & $2.16(1.64-2.85)$ & $<0.0001$ \\
\hline Witnessed $(0 / 1)$ & $406(92)$ & $427(87)$ & $0.61(0.39-0.97)$ & 0.04 \\
\hline Bystander CPR (0/2) & $347(79)$ & $331(67)$ & $0.61(0.45-0.83)$ & 0.002 \\
\hline First monitored rhythm other than VTNF $(0 / 1)$ & $38(9)$ & $169(34)$ & $5.14(3.46-7.64)$ & $<0.0001$ \\
\hline Intubation (6/8) & $273(63)$ & $352(73)$ & $1.67(1.24-2.25)$ & 0.0007 \\
\hline CA until BLS (73/141) & $1(0-2)$ & $1(0-3)$ & $1.10(1.04-1.17)$ & 0.0005 \\
\hline CA until ALS (8/8) & $8(5-11)$ & $10(7-15)$ & $1.07(1.04-1.10)$ & $<0.0001$ \\
\hline CA until ROSC $(0 / 1)$ & $20(14-30)$ & $31(21-47)$ & $1.57(1.42-1.72)^{c}$ & $<0.0001$ \\
\hline No flow ${ }^{d}(2 / 4)$ & $1(0-3)$ & $2(0-8)$ & $1.09(1.05-1.12)$ & $<0.0001$ \\
\hline Low flow ${ }^{e}(0 / 1)$ & $19(12-27)$ & $27(17-40)$ & $1.43(1.31-1.56)^{c}$ & $<0.0001$ \\
\hline Adrenaline (3/2) & $258(59)$ & $423(86)$ & $4.62(3.29-6.48)$ & $<0.0001$ \\
\hline Seizures (1/2) & $33(8)$ & $23(5)$ & $0.64(0.36-1.15)$ & 0.14 \\
\hline Automatic compression (0/3) & $92(21)$ & $127(26)$ & $1.27(0.92-1.75)$ & 0.15 \\
\hline
\end{tabular}

Abbreviations: CA Cardiac arrest, CPC Cerebral Performance Category, CPR Cardiopulmonary resuscitation, VTNF Ventricular tachycardia/ventricular fibrillation, BLS Basic life support, ALS Advanced life support, ROSC Return of spontaneous circulation

Data are presented as number (\%) or median (25th and 75th percentiles)

Poor outcome defined as CPC 3-5 at 6 months

${ }^{\mathrm{a}} \mathrm{OR}$ for poor outcome (CPC 3-5) with corresponding $95 \% \mathrm{Cl}$

${ }^{b}$ Number missing in the two groups, respectively

'Square root transformed

${ }^{d}$ No flow: time from CA to start of CPR measured in minutes

e Low flow: time from start of CPR to ROSC measured in minutes

\section{Results}

A total of 939 patients were included in the original TTM trial. Neurological outcome data 6 months after CA were available for 933 (99\%) patients, who consequently were included in the present analysis. Of these patients, 493 (52\%) had a poor outcome of CPC 3-5. Their median age was 65 years (IQR $57-73$ years), and 177 (19\%) were female.

\section{Variables associated with a poor outcome}

Older age, female sex, higher body mass index and a previous history of alcoholism were associated with a poor outcome (Table 1). Longer time from collapse to arrival of providers of BLS and ALS, as well as initial rhythm other than ventricular tachycardia or ventricular fibrillation (VT/VF), was associated with a poor outcome. CA location at home, longer duration of no flow and low flow, increasing time to ROSC and pre-hospital intubation and administration of adrenaline were also associated with a poor outcome (Table 2).

Lower $\mathrm{pH}$, base excess and initial body temperature were associated with a poor outcome. Absence of brainstem reflexes, such as spontaneous breathing as well as pupillary, corneal and cough reflexes, were also associated with a poor outcome. Associated with a poor outcome were higher lactate; initial shock; higher glucose, potassium and creatinine in plasma; and absence of motor response at pain stimulation (Glasgow Coma
Scale motor score 1 [GCS-M1]). Abnormal partial pressure of carbon dioxide in arterial blood $\left(\mathrm{PaCO}_{2} ;<4.5\right.$ or $>6.0 \mathrm{kPa}$ ) in initial blood gas samples was also associated with a poor outcome (Table 3).

\section{Independent predictors of a poor outcome}

Six variables were excluded from the multivariate analysis because of multicollinearity: CA to BLS and CA to ALS were highly correlated to no flow, and CA to ROSC to low flow and lactate, blood glucose and base excess were all correlated to $\mathrm{pH}$. After stepwise backward elimination, ten variables remained significantly correlated to a poor outcome: older age, CA occurring at home, initial rhythm other than VF/VT, longer duration of no flow, longer duration of low flow, treatment with adrenaline, bilateral absence of corneal and pupillary reflexes, GCS-M1, a lower $\mathrm{pH}$ and a $\mathrm{PaCO}_{2}$ lower than $4.5 \mathrm{kPa}$ on admission (Table 4). This final model showed good discrimination with a median (range) AUC of 0.844 (0.842-0.846) and a median AUC of 0.820 by internal validation with bootstrap-derived samples correcting for optimism. The Hosmer-Lemeshow goodness-of-fit test demonstrated overall good calibration with $p>0.40$ for all 50 imputations.

\section{A simple risk score for a poor outcome: performance and validation}

The TTM risk score was developed using the final selection of variables above. The points assigned to different 
Table 3 Patient factors based on examination on arrival at hospital

\begin{tabular}{|c|c|c|c|c|c|}
\hline & \multicolumn{2}{|c|}{ Outcome at 6 months } & \multirow[b]{2}{*}{$p$ Value } & \multicolumn{2}{|l|}{ Adjusted for age } \\
\hline & $\overline{C P C} 1-2(n=440)$ & CPC 3-5 $(n=493)$ & & $\mathrm{OR}(95 \% \mathrm{Cl})^{\mathrm{a}}$ & $p$ Value \\
\hline Initial temperature $(12 / 23)^{b}$ & $35.5(34.9-36.0)$ & $35.3(34.4-36.0)$ & 0.002 & $0.11(0.03-0.47)$ & 0.003 \\
\hline Pupillary/corneal reflex (8/36) & $392(91)$ & $327(72)$ & $<0.0001$ & $0.27(0.18-0.40)$ & $<0.0001$ \\
\hline Cough reflex (45/59) & $277(70)$ & $211(49)$ & $<0.0001$ & $0.41(0.30-0.55)$ & $<0.0001$ \\
\hline Spontaneous breathing (15/22) & $310(73)$ & $284(60)$ & $<0.0001$ & $0.57(0.43-0.77)$ & 0.0002 \\
\hline GCS-M1 (1/6) & $173(39)$ & $316(65)$ & $<0.0001$ & $2.79(2.11-3.70)$ & $<0.0001$ \\
\hline $\mathrm{pH}(24 / 20)$ & $7.27(7.17-7.32)$ & 7.19 (7.05-7.28) & $<0.0001$ & $0.02(0.01-0.06)$ & $<0.0001$ \\
\hline Lactate $(36 / 25)$ & $4.6(2.4-8.1)$ & $6.9(3.9-10.6)$ & $<0.0001$ & $1.84(1.55-2.20)^{c}$ & $<0.0001$ \\
\hline Creatinine (13/17) & $95(80-115)$ & $115(90-140)$ & $<0.0001$ & $3.36(2.14-5.29)^{d}$ & $<0.0001$ \\
\hline Blood glucose (32/20) & $12.4(9.4-16.0)$ & $14.0(10.6-18.0)$ & $<0.0001$ & $1.08(1.06-1.12)$ & $<0.0001$ \\
\hline $\mathrm{PaCO}_{2}(31 / 25)$ & & & 0.0006 & & 0.0004 \\
\hline$<4.5 \mathrm{kPa}$ & $40(10)$ & $66(14)$ & & $1.96(1.22-3.16)$ & \\
\hline$>6.0 \mathrm{kPa}$ & $191(47)$ & $256(55)$ & & $1.75(1.29-2.38)$ & \\
\hline Base excess (40/26) & $-6(-10,-4)$ & $-10(-15,-5)$ & $<0.0001$ & $0.93(0.91-0.95)$ & $<0.0001$ \\
\hline Potassium (15/13) & $3.7(3.4-4.2)$ & $4.0(3.5-4.5)$ & $<0.0001$ & $1.55(1.29-1.87)$ & $<0.0001$ \\
\hline Shock at admission (0/1) & $36(8)$ & $100(20)$ & $<0.0001$ & $2.70(1.77-4.13)$ & $<0.0001$ \\
\hline $\mathrm{PaO}_{2}>40 \mathrm{kPa}(35 / 35)$ & $64(16)$ & $95(21)$ & 0.07 & $1.38(0.96-2.00)$ & 0.09 \\
\hline $\mathrm{FiO}_{2}, \%(11 / 20)$ & $80(50-100)$ & $90(53-100)$ & 0.21 & $1.00(1.00-1.01)$ & 0.25 \\
\hline Acute STEMI/LBBB (2/8) & $217(50)$ & $220(45)$ & 0.21 & $0.96(0.73-1.26)$ & 0.77 \\
\hline
\end{tabular}

Abbreviations: CPC Cerebral Performance Category, GCS-M1 Glasgow Coma Scale motor score 1, $\mathrm{PaCO}_{2}$ Partial pressure of carbon dioxide in arterial blood, $\mathrm{PaO}{ }_{2}$ Partial pressure of oxygen in arterial blood, $\mathrm{FiO}_{2}$ Fraction of inspired oxygen, STEMI ST segment elevation myocardial infarction, $L B B B$ Left bundle branch block Patients with abnormal values of $\mathrm{PaCO}_{2}(<4.5$ or $>6.0 \mathrm{kPa}$, respectively) were compared with patients with normal values

Data are presented as number (\%) or median (25th and 75 th percentiles)

Poor outcome defined as CPC 3-5 at 6 months

${ }^{\mathrm{a}} \mathrm{OR}$ for poor outcome (CPC 3-5), with corresponding $95 \% \mathrm{Cl}$

${ }^{b}$ Number missing in the two groups, respectively

'Square root transformed

${ }^{\mathrm{d}}$ Transformed by the natural logarithm

Table 4 Independent predictors of Cerebral Performance Category 3-5 at 6 months

\begin{tabular}{|c|c|c|c|}
\hline & OR $(95 \% \mathrm{Cl})$ & $p$ Value & $\beta$ - Coefficient \\
\hline Age, years & $1.07(1.05-1.08)$ & $<0.0001$ & 0.0644 \\
\hline CA at home & $1.75(1.26-2.44)$ & 0.0008 & 0.5620 \\
\hline First monitored rhythm other than VTNF & $4.06(2.55-6.46)$ & $<0.0001$ & 1.4014 \\
\hline No flow, minutes & $1.06(1.02-1.10)$ & 0.002 & 0.0578 \\
\hline Low flow, minutes & $1.28(1.15-1.42)^{a}$ & $<0.0001$ & 0.2430 \\
\hline Treatment with adrenaline & $2.08(1.39-3.11)$ & 0.0003 & 0.7342 \\
\hline No pupillary or corneal reflex & $2.46(1.58-3.85)$ & $<0.0001$ & 0.9016 \\
\hline $\mathrm{pH}$ & $0.10(0.03-0.34)$ & 0.0003 & 2.3308 \\
\hline GCS motor score $1^{\mathrm{b}}$ & $2.00(1.44-2.77)$ & $<0.0001$ & 0.6927 \\
\hline $\mathrm{PaCO}_{2}<4.5 \mathrm{kPa}$ & $2.53(1.46-4.39)$ & 0.0009 & 0.9293 \\
\hline
\end{tabular}

Abbreviations: CA Cardiac arrest, GCS Glasgow Coma Scale, $\mathrm{PaCO}_{2}$ Partial pressure of carbon dioxide in arterial blood, VT/VF Ventricular

tachycardia/ventricular fibrillation

${ }^{\text {a }}$ Square root-transformed values

${ }^{\mathrm{b}} \mathrm{GCS}$ motor score $1=$ no motor reaction to a painful stimuli 
variables are listed in Table 5. The minimum sum of points was -2 , and the maximum was 35 . The performance of the TTM score using quartiles as cut-offs is described in Table 6. The median (range) AUC was $0.842(0.840-0.845)$, and corrected for optimism by internal validation it was $0.818(0.816-0.821)$. The Hosmer-Lemeshow goodness-of-fit test yielded a $p$ value $>0.10$ in all 50 imputations, showing good calibration. The median concordance percentage was 82.2 (range $81.0-82.5)$. In patients with a score above 13 points, the sensitivity for poor outcome was $69 \%$ to $70 \%$ with a corresponding specificity of $83 \%$ to $84 \%$.

\section{Risk for a poor outcome assessed by OHCA and CAPH scores}

On the basis of the formula presented by Adrie et al. [11], we calculated the OHCA risk score in our cohort for each of the 50 imputations. This rendered a median (range) AUC of $0.746(0.739-0.752)$, and 48 of the 50 imputations (96\% of the imputed datasets) had a $p$ value $<0.05$ for the Hosmer-Lemeshow goodness-of-fit test, indicating poor calibration. Median (range) concordance was 74.4 (73.8-75.1). For patients with a high risk according to the original paper (score $>32.5$ ), the sensitivity was $44 \%$ to $45 \%$ and the specificity was $89 \%$ to $89 \%$ for a poor outcome.

By visually estimating the parameters in the risk score model presented by Maupain et al. [12], we also calculated the CAHP risk score in our cohort for each of the 50 imputations, yielding a median (range) AUC of 0.746 (0.743-0.747), and 20 (40\%) of the 50 imputations had $p$ values $<0.05$ for the Hosmer-Lemeshow goodness-of-fit test, indicating poor calibration. The median (range) concordance percentage was 74.3 (74.0-74.6). In patients with a score above 200 points, which Maupain et al. defined as high risk, the sensitivity for poor outcome was $48 \%$ to $49 \%$ with a corresponding specificity of $82 \%$ to $83 \%$.

The performance of the OHCA and CAHP scores is shown in Table 6. A comparison of the performance using ROC curves of the three risk scores is presented in Fig. 1.

\section{Discussion}

The aim of this study was to identify independent parameters from patient history and status available at intensive care admission that could be used for early prediction and risk stratification of a poor outcome in comatose survivors following OHCA. Age, time to ROSC and initial temperature were previously reported from the TTM cohort [21, 23, 24]. Our findings using multiple variable analysis are also in line with earlier studies that older age, CA occurring at home, initial rhythm other than VF/VT, longer duration of no flow,
Table 5 Target temperature management risk score points (range -2 to 35 )

\begin{tabular}{|c|c|c|}
\hline Risk factor & Categories & Points \\
\hline \multirow[t]{11}{*}{ Age, years } & $<40$ & -1 \\
\hline & $40-44$ & 0 \\
\hline & $45-49$ & 1 \\
\hline & $50-54$ & 2 \\
\hline & $55-59$ & 3 \\
\hline & $60-64$ & 4 \\
\hline & $65-69$ & 5 \\
\hline & $70-74$ & 6 \\
\hline & $75-79$ & 7 \\
\hline & $80-84$ & 8 \\
\hline & $\geq 85$ & 9 \\
\hline \multirow[t]{2}{*}{ CA at home } & No & 0 \\
\hline & Yes & 2 \\
\hline \multirow[t]{2}{*}{ First monitored rhythm other than VTNF } & No & 0 \\
\hline & Yes & 4 \\
\hline \multirow[t]{4}{*}{ No flow } & $0-4$ & 0 \\
\hline & $5-9$ & 1 \\
\hline & $10-14$ & 2 \\
\hline & $\geq 15$ & 3 \\
\hline \multirow[t]{5}{*}{ Low flow } & $0-5$ & 0 \\
\hline & $6-15$ & 1 \\
\hline & $16-30$ & 2 \\
\hline & $31-60$ & 3 \\
\hline & $>60$ & 4 \\
\hline \multirow[t]{2}{*}{ Treatment with adrenaline } & No & 0 \\
\hline & Yes & 2 \\
\hline \multirow[t]{2}{*}{ No pupillary or corneal reflex } & No & 0 \\
\hline & Yes & 3 \\
\hline \multirow[t]{5}{*}{$\mathrm{pH}$} & $\geq 7.35$ & -1 \\
\hline & $7.20-7.34$ & 0 \\
\hline & $7.05-7.19$ & 1 \\
\hline & $6.90-7.04$ & 2 \\
\hline & $<6.90$ & 3 \\
\hline \multirow[t]{2}{*}{ GCS motor score 1} & No & 0 \\
\hline & Yes & 2 \\
\hline \multirow[t]{2}{*}{$\mathrm{PaCO}_{2}<4.5 \mathrm{kPa}$} & No & 0 \\
\hline & Yes & 3 \\
\hline
\end{tabular}

Abbreviations: CA Cardiac arrest, GCS Glasgow Coma Scale, $\mathrm{PaCO}_{2}$ Partial pressure of carbon dioxide in arterial blood, VTNF Ventricular tachycardia/ventricular fibrillation

Points assigned to categories of the ten independent risk factors for a poor outcome in the calculation of the Target temperature management risk score. Poor outcome was defined as Cerebral Performance Category 3-5 at 6 months after out-of-hospital cardiac arrest. Total score ranged from -2 to 35 . No flow is defined as time from CA to start of cardiopulmonary resuscitation in minutes. Low flow is defined as time from start of cardiopulmonary resuscitation to return of spontaneous circulation in minutes 
Table 6 Discrimination performance of the three risk scores

\begin{tabular}{llll}
\hline Risk score & Scores & & \\
\hline TTM risk score & $>10$ & $>13$ & $>16$ \\
$n$ (\%) & $612-615(66-66)$ & $410-417$ (44-45) & $217-221$ (23-24) \\
Sensitivity, \% & $86-87$ & $69-70$ & $40-41$ \\
Specificity, \% & $57-58$ & $83-84$ & $95-96$ \\
PPV, \% & $69-70$ & $82-83$ & $91-91$ \\
NPV, \% & $79-80$ & $71-71$ & $59-59$ \\
CAHP risk score & $>150$ & $>200$ & \\
$n$ (\%) & $711-716$ (76-77) & $312-318$ (33-34) \\
Sensitivity, \% & $91-91$ & $48-49$ & \\
Specificity, \% & $39-40$ & $82-83$ & \\
PPV, \% & $63-63$ & $76-76$ & \\
NPV, \% & $79-79$ & $59-59$ & \\
OHCA risk score & $>2.0$ & $>17.4$ & $>32.5$ \\
$n$ (\%) & $829-833$ (89-89) & $565-574(62-62)$ & $266-271$ (29-29) \\
Sensitivity, \% & $94-94$ & $77-78$ & $44-45$ \\
Specificity, \% & $16-17$ & $56-58$ & $89-89$ \\
PPV, \% & $56-56$ & $66-67$ & $82-82$ \\
NPV, \% & $71-73$ & $69-70$ & $59-59$ \\
\hline Abbrvatons: CAHP Car & &
\end{tabular}

Abbreviations: CAHP Cardiac Arrest Hospital Prognosis, NPV Negative predictive value, PPV Positive predictive value, ROSC Return of spontaneous circulation, TTM Target Temperature Management trial

Discrimination performance of the three different risk scores in our TTM trial cohort with minimum-maximum values of the first five imputations. The TTM risk score is divided into quartiles where the Youden's J statistic cut-off ( $>13$ points) coincides with second quartile upper limit (i.e., the median). The CAHP and OHCA risk scores are calculated and divided as described in their respective original publications $[11,12]$. They were defined as high risk if $>200$ points and $>32.5$ points for the CAHP and OHCA risk scores, respectively

longer duration of low flow, treatment with adrenaline, absence of corneal and pupillary reflexes, GCS$\mathrm{M} 1$, a lower $\mathrm{pH}$, and a $\mathrm{PaCO}_{2}$ lower than $4.5 \mathrm{kPa}$ on admission were independent predictors of a poor outcome $[2,6,11,18-20,25-36]$. Low-flow time from the initiation of CPR to ROSC has previously been associated with a poor outcome in various studies of OHCA [11, 29, 37], including the present cohort [21]. However, effective low flow may have been longer than registered because BLS was provided before arrival of ALS in $73 \%$ of the patients. Notwithstanding that BLS efficacy may vary considerably and is difficult to assess, registered low-flow time in the present study was somewhat longer than reported in the cohorts used to calculate OHCA and CAHP risk scores $[11,12]$. The role of adrenaline in the resuscitation of OHCA victims is controversial, and in a recent metaanalysis, no benefit could be found [30]. In a Japanese study of 400,000 patients, researchers reported increased ROSC but decreased 1-month survival in patients who received adrenaline compared with those who did not [31]. Adrenaline is still part of European

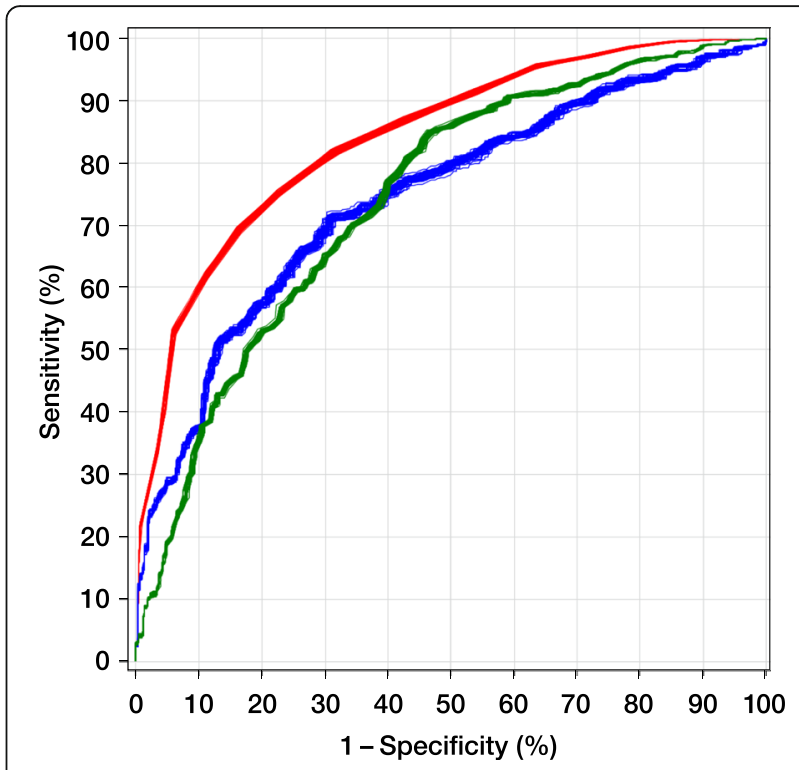

Fig. 1 Comparison of the performance of the Target Temperature Management (TTM), out-of-hospital cardiac arrest (OHCA) and Cardiac Arrest Hospital Prognosis (CAHP) risk scores. ROC curves for a poor outcome at 6 months for the TTM (red), OHCA (blue) and CAHP (green) risk scores in our imputed sample (one curve per score for each of the 50 imputations). The median AUC for the TTM score was 0.842 (0.818 corrected for optimism); for the OHCA score, it was 0.746 , and for the CAHP score, it was 0.746

resuscitation guidelines [38], and it is possible that the association between adrenaline and a poor outcome that we found was related to more complicated resuscitations. Among variables potentially available at ICU admission, co-morbidity may be expected to be important. However, as in this analysis, it has previously been shown not to be associated with mortality in the present patient cohort [39].

To assess the risk for poor outcome after OHCA at an early stage, we constructed the TTM risk score on the basis of individual variables available at ICU admission. Several prediction methods have previously been investigated. The Acute Physiology and Chronic Health Evaluation II score [40], which is not disease-specific, has repeatedly been shown to be a poor predictor of outcome in OHCA [41]. The OHCA risk score presented in 2006 using variables available at hospital admission showed a similar performance. However, the OHCA risk score was based on a small cohort $(n=130)$. Also, the patients were relatively young compared with other OHCA cohorts, with a median age of 55 years and no patients older than 69 years [11]. The recently published CAHP risk score, based on a large number of patients, has performed best so far with an AUC of 0.93. However, some steps in its underlying calculations, such as the assumption of a linear association between outcome and time to ROSC, as well as outcome and $\mathrm{pH}$, can be discussed [12]. When applied 
in our cohort, the OHCA and the CAPH scores lost performance as assessed by AUC, sensitivity, specificity, positive predictive value (PPV) and negative predictive value (NPV). These discrepancies reflect the problem of low external validity for scores that are constructed in a single cohort. This may also apply to our score in spite of our use of a multicentre international cohort, and it needs to be validated in further trials. For the TTM risk score, a high value ( $>16$ points, representing the fourth quartile of the patients) showed a promising PPV of $91 \%$ and a specificity of $95 \%$ to $96 \%$ and therefore indicated an acceptable margin not to predict a poor outcome in a patient with a good prognosis. However, the corresponding sensitivity was only $43 \%$. Selecting a performance optimum cut-off of $>13$ points by use of Youden's J statistics, yielding a sensitivity and specificity of $69 \%$ to $70 \%$ and $83 \%$ to $84 \%$, respectively, does not render the score more useful, because the PPV is reduced to $82 \%$ to $83 \%$. A low sensitivity when reaching a satisfactory specificity was also an issue for the CAHP risk score (sensitivity $46 \%$ to $56 \%$ in the development cohort). The high-risk cut-off OHCA score at 32.5 points (development cohort) described in the paper had an inadequate specificity of only $77 \%$ for poor outcome but a better sensitivity of $77 \%$ [11]. These results provoke the question whether better performance could be achieved with more, or contrarily, with fewer but highly discriminative, variables in a risk score model. Interestingly, Jabre et al. [42], using a development cohort of 1771 patients, found $0 \%$ (95\% CI $0.0 \%$ to $0.5 \%$ ) survival in 772 patients who fulfilled three criteria during pre-hospital resuscitation. These criteria were (1) OHCA not witnessed by emergency medical services personnel, (2) nonshockable initial cardiac rhythm and (3) no ROSC before receipt of a third 1-mg dose of epinephrine. However, comparison with our TTM trial cohort is difficult because the latter included only patients hospitalised alive after OHCA. Among 618 patients admitted alive in the Jabre et al. study, $22 \%$ were discharged alive. There is no information about the 180 -day survival, which was close to $50 \%$ in the TTM cohort [15].

\section{Strengths and limitations}

A significant advantage of the present study is the welldefined cohort of patients who were carefully evaluated. In particular, on one hand, a major strength was that patients in the TTM trial were subject to strict rules on neurological prognostication and withdrawal of lifesustaining therapy [15], which may be a significant source of bias in cohort studies and other randomised clinical trials. On the other hand, our risk score is valid only under these clinical conditions. A large number of clinically relevant variables and outcome measures were registered in similar pre-hospital and emergency health care systems and ICUs following a published trial protocol [16]. This may favour evaluation of heterogeneous early predictors of outcome [9]. Treating all patients included in a randomised trial of two interventions as one cohort carries a principal risk of hiding differences between the groups. However, the two groups were well balanced with regard to background characteristics and the main outcome, and outcomes in numerous sub-studies have shown no differences due to the intervention. Nevertheless, it needs to be stressed that a major limitation of the external validity of our study is that the cohort consists of selected patients with OHCA of a presumed cardiac origin who were not found in unwitnessed asystole, who were unconscious on admission to hospital and who were not in a refractory circulatory shock state. Furthermore, the modality or the degree of respiratory support before ICU admission constitutes a treatment bias because it was not registered in this study and could have affected predictors such as $\mathrm{PaCO}_{2}$ and $\mathrm{pH}$.

\section{Conclusions}

In a cohort of 933 patients with OHCA of a presumed cardiac cause extracted from the 939 patients included in the TTM trial, we found ten independent predictors of a poor outcome, defined as CPC 3-5 six months after CA. These included older age, CA occurring at home, initial rhythm other than VT/VF, longer duration of no flow, longer duration of low flow, administration of adrenaline, bilaterally absent pupillary and corneal reflexes, absent motor response to pain, a lower $\mathrm{pH}$, and a $\mathrm{PaCO}_{2}$ lower than $4.5 \mathrm{kPa}$ at admission.

The predictors readily available at ICU admission were used to construct an easy and simple-to-use risk score that showed good association with outcome 6 months after the arrest. The score could further represent a helpful tool for treatment allocation and stratification in randomised studies as well as for comparison of cohorts in epidemiological studies. However, it is important to stress that the proposed risk score is not yet precise enough to be used for individual prognostication of outcome after OHCA, and it needs further validation in a large cohort of patients with OHCA.

\footnotetext{
Abbreviations

ALS: Advanced life support; AMI: Acute myocardial infarction; BLS: Basic life support; BMI: Body mass index; CA: Cardiac arrest; CABG: Coronary artery bypass grafting; CAHP: Cardiac Arrest Hospital Prognosis; COPD: Chronic obstructive pulmonary disease; CPC: Cerebral Performance Category; CPR: Cardiopulmonary resuscitation; $\mathrm{FiO}_{2}$ : Fraction of inspired oxygen; GCS: Glasgow Coma Scale; GCS-M1: Glasgow Coma Scale motor score 1; ICD: Implantable cardioverter defibrillator; ICU: Intensive care unit; IHD: Intermittent haemodialysis; LBBB: Left bundle branch block; NPV: Negative predictive value; OHCA: Out-of-hospital cardiac arrest; $\mathrm{PaCO}_{2}$ : Partial pressure of carbon dioxide in arterial blood; $\mathrm{PaO}_{2}$ : Partial pressure of oxygen in arterial blood; PCl: Percutaneous coronary intervention; PPV: Positive predictive value; ROSC: Return of spontaneous circulation; STEMI: ST segment elevation myocardial infarction; TIA: Transient ischaemic attack; TTM: Target Temperature Management trial; VTNF: Ventricular tachycardia/ventricular fibrillation
} 


\section{Acknowledgements}

The authors are indebted to the investigators of the TTM trial.

\section{Funding}

This study was supported by the Arbetsmarknadens Försäkringsaktiebolag Insurance Foundation, the Swedish Research Council, Region Skåne (Sweden), the National Health Service (Sweden), the Thelma Zoega Foundation, the Krapperup Foundation, the Thure Carlsson Foundation, the Hans-Gabriel and Alice Trolle-Wachtmeister Foundation for Medical Research, TrygFonden (Denmark), the European Clinical Research Infrastructures Network and the Swedish Heart-Lung Foundation.

\section{Availability of data and materials}

The data and materials used in the present study are available on request from the corresponding author.

\section{Authors' contributions}

LM participated in the design of the study and drafted and revised the manuscript. NN contributed to the creation of the study material, participated in the design of the study and helped to revise the manuscript. JHe participated in the design of the study and helped to revise the manuscript. TK participated in the design of the study, performed the statistical analyses and helped to revise the manuscript. JHo contributed to the creation of the study material and helped to revise the manuscript. MPW contributed to the creation of the study material and helped to revise the manuscript. JU contributed to the creation of the study material and helped to revise the manuscript. CR participated in the design of the study and drafted and revised the manuscript. All authors read and approved the final manuscript and take full responsibility for all aspects of the study.

\section{Competing interests}

MPW was funded 40\% WTE during the study by a National Institute for Social Care and Health Research (NISCHR) Academic Health Science Collaboration (AHSC) Clinical Research Fellowship; received reimbursement for travel costs from the British Thoracic Society, the Intensive Care Society, the Scottish Intensive Care Society, and Orion Ltd.; royalties from Willey Publishing; and honoraria from Fisher \& Paykel, and Merck for lecturing at an educational meeting. MPW also serves on the advisory board for Kalobius Pharmaceuticals, and served on an advisory board for Bard in 2010. MPW also is an editor of BMJ Open Respiratory Research. The other authors declare that they have no competing interests.

\section{Consent for publication}

Not applicable.

\section{Ethics approval and consent to participate}

Ethical approval was granted according to national requirements, and the need for written informed consent was waived, delayed or obtained from a legal surrogate, depending on the circumstances.

Australia: Health Ethics Review Committee (protocol numbers X11-0150 and HREC/11/RPAH/216 - GI-CCT886).

Czech Republic: Ethics committee of the General University Hospital of Prague (c/j 193-11 S 17.2.2011).

Denmark: De vitenskabsetiske Komiteer i Region Hovedstaden (H-1-2010059).

Italy: Comitato Etico Indipendente, Hospedaliera S Maria degli Angeli Pordenone (number 9).

Luxembourg: Comité National d'Ethique de Recherche (CNER) (number 201007/05 version 1.0)

The Netherlands: Medisch Etische Toetsingscommissie (MEC 10/107 \# 10.17.0921).

Norway: Regional komité for medisinsk och helsefaglig forskningsetikk Sørøst C reference 2010/384.

Sweden: Regional Ethical Review Board Lund protocol 2009/6 Dnr 2009/324 (TTM trial).

Switzerland: Comité d'Ethique de Recherche CER 10-254 (NAC 10-088). United Kingdom: Cardiff and Vale Research Review Service (project ID 10/ AIC/4927), Research Ethics Committee for Wales (10/MRE09/41).

\section{Publisher's Note}

Springer Nature remains neutral with regard to jurisdictional claims in published maps and institutional affiliations.

\section{Author details}

${ }^{1}$ Department of Anaesthesiology and Intensive Care Medicine, Institute of Clinical Sciences, Sahlgrenska Academy, University of Gothenburg, SE-413 45 Gothenburg, Sweden. '2Department of Clinical Sciences, Lund University, Lund, Sweden. ${ }^{3}$ The Centre for Pre-hospital Research in Western Sweden, University College of Borås and Sahlgrenska University Hospital, Gothenburg, Sweden. ${ }^{4}$ Health Metrics at Sahlgrenska Academy, University of Gothenburg, Gothenburg, Sweden. ${ }^{5}$ Department of Intensive Care, Academic Medical Centre, University of Amsterdam, Amsterdam, The Netherlands. ${ }^{6}$ Adult Critical Care, University Hospital of Wales, Cardiff, UK. ${ }^{7}$ Department of Intensive Care and Perioperative Medicine, Lund University, Malmö, Sweden.

Received: 10 December 2016 Accepted: 22 March 2017

Published online: 13 April 2017

\section{References}

1. Tømte $\varnothing$, Andersen G $\varnothing$, Jacobsen D, Drægni T, Auestad B, Sunde K. Strong and weak aspects of an established post-resuscitation treatment protocol_a five-year observational study. Resuscitation. 2011;82(9):1186-93.

2. Nielsen N, Hovdenes J, Nilsson F, Rubertsson S, Stammet P, Sunde K, et al. Outcome, timing and adverse events in therapeutic hypothermia after outof-hospital cardiac arrest. Acta Anaesthesiol Scand. 2009;53(7):926-34.

3. Shinozaki K, Oda S, Sadahiro T, Nakamura M, Hirayama Y, Watanabe E, et al. Blood ammonia and lactate levels on hospital arrival as a predictive biomarker in patients with out-of-hospital cardiac arrest. Resuscitation. 2011; 82(4):404-9.

4. Larsen MP, Eisenberg MS, Cummins RO, Hallstrom AP. Predicting survival from out-of-hospital cardiac arrest: a graphic model. Ann Emerg Med. 1993; 22(11):1652-8

5. Müllner M, Sterz F, Domanovits $H$, Behringer W, Binder M, Laggner AN. The association between blood lactate concentration on admission, duration of cardiac arrest, and functional neurological recovery in patients resuscitated from ventricular fibrillation. Intensive Care Med. 1997:23(11):1138-43.

6. Wibrandt I, Norsted K, Schmidt H, Schierbeck J. Predictors for outcome among cardiac arrest patients: the importance of initial cardiac arrest rhythm versus time to return of spontaneous circulation, a retrospective cohort study. BMC Emerg Med. 2015;15:3.

7. Herlitz J, Bång A, Gunnarsson J, Engdahl J, Karlson BW, Lindqvist J, et al. Factors associated with survival to hospital discharge among patients hospitalised alive after out of hospital cardiac arrest: change in outcome over 20 years in the community of Göteborg, Sweden. Heart. 2003;89(1):25-30.

8. Fredriksson M, Herlitz J, Nichol G. Variation in outcome in studies of out-ofhospital cardiac arrest: a review of studies conforming to the Utstein guidelines. Am J Emerg Med. 2003;21(4):276-81.

9. Nishiyama C, Brown SP, May S, Iwami T, Koster RW, Beesems SG, et al. Apples to apples or apples to oranges? International variation in reporting of process and outcome of care for out-of-hospital cardiac arrest. Resuscitation. 2014:85(11):1599-609.

10. Nolan JP, Soar J, Cariou A, Cronberg T, Moulaert VRM, Deakin CD, et al. European Resuscitation Council and European Society of Intensive Care Medicine 2015 guidelines for post-resuscitation care. Intensive Care Med. 2016;41(12):2039-56. A published erratum appears in Intensive Care Med. 2016;42(3):488-9.

11. Adrie C, Cariou A, Mourvillier B, Laurent I, Dabbane H, Hantala F, et al. Predicting survival with good neurological recovery at hospital admission after successful resuscitation of out-of-hospital cardiac arrest: the OHCA score. Eur Heart J. 2006:27(23):2840-5.

12. Maupain C, Bougouin W, Lamhaut L, Deye N, Diehl JL, Geri G, et al. The CAHP (Cardiac Arrest Hospital Prognosis) score: a tool for risk stratification after out-of-hospital cardiac arrest. Eur Heart J. 2016;37(42):3222-8.

13. Skrifvars MB, Varghese B, Parr MJ. Survival and outcome prediction using the Apache III and the out-of-hospital cardiac arrest (OHCA) score in patients treated in the intensive care unit (ICU) following out-of-hospital, inhospital or ICU cardiac arrest. Resuscitation. 2012;83(6):728-33.

14. Jennett B, Bond M. Assessment of outcome after severe brain damage: a practical scale. Lancet. 1975;305(7905):480-4. 
15. Nielsen N, Wetterslev J, Cronberg T, Erlinge D, Gasche Y, Hassager C, et al. Targeted temperature management at $33^{\circ} \mathrm{C}$ versus $36{ }^{\circ} \mathrm{C}$ after cardiac arrest. N Engl J Med. 2013;369(23):2197-206.

16. Nielsen N, Wetterslev J, Al-Subaie N, Andersson B, Bro-Jeppesen J, Bishop G, et al. Target temperature management after out-of-hospital cardiac arrest - a randomized, parallel-group, assessor-blinded clinical trial—rationale and design. Am Heart J. 2012;163(4):541-8.

17. Langhelle A, Nolan J, Herlitz J, Castren M, Wenzel V, Soreide E, et al. Recommended guidelines for reviewing, reporting, and conducting research on post-resuscitation care: the Utstein style. Resuscitation. 2005; 66(3):271-83.

18. Frydland $\mathrm{M}$, Kjaergaard J, Erlinge D, Wanscher $\mathrm{M}$, Nielsen $\mathrm{N}$, Pellis $\mathrm{T}$, et al. Target temperature management of $33^{\circ} \mathrm{C}$ and $36^{\circ} \mathrm{C}$ in patients with outof-hospital cardiac arrest with initial non-shockable rhythm - a TTM substudy. Resuscitation. 2015;89:142-8.

19. Annborn M, Bro-Jeppesen J, Nielsen N, Ullén S, Kjaergaard J, Hassager C, et al. The association of targeted temperature management at 33 and $36{ }^{\circ} \mathrm{C}$ with outcome in patients with moderate shock on admission after out-of-hospital cardiac arrest: a post hoc analysis of the Target Temperature Management trial. Intensive Care Med. 2014;40(9):1210-9.

20. Winther-Jensen M, Kjaergaard J, Wanscher M, Nielsen N, Wetterslev J, Cronberg T, Erlinge D, Friberg H, Gasche Y, Horn J, et al. No difference in mortality between men and women after out-of-hospital cardiac arrest. Resuscitation. 2015;96:78-84.

21. Kjaergaard J, Nielsen N, Winther-Jensen M, Wanscher M, Pellis T, Kuiper M, et al. Impact of time to return of spontaneous circulation on neuroprotective effect of targeted temperature management at 33 or 36 degrees in comatose survivors of out-of hospital cardiac arrest. Resuscitation. 2015;96:310-6.

22. Sullivan LM, Massaro JM, D'Agostino Sr RB. Presentation of multivariate data for clinical use: the Framingham Study risk score functions. Stat Med. 2004; 23(10):1631-60.

23. Hovdenes J, Røysland K, Nielsen N, Kjaergaard J, Wanscher M, Hassager C, et al. A low body temperature on arrival at hospital following out-of-hospitalcardiac-arrest is associated with increased mortality in the TTM-study. Resuscitation. 2016;107:102-6.

24. Winther-Jensen M, Pellis T, Kuiper M, Koopmans M, Hassager C, Nielsen N, et al. Mortality and neurological outcome in the elderly after target temperature management for out-of-hospital cardiac arrest. Resuscitation. 2015:91:92-8.

25. Herlitz J, Engdahl J, Svensson L, Ängquist KA, Young M, Holmberg S. Factors associated with an increased chance of survival among patients suffering from an out-of-hospital cardiac arrest in a national perspective in Sweden. Am Heart J. 2005;149(1):61-6.

26. Swor RA, Jackson RE, Tintinalli JE, Pirrallo RG. Does advanced age matter in outcomes after out-of-hospital cardiac arrest in community-dwelling adults? Acad Emerg Med. 2000;7(7):762-8.

27. Fridman M, Barnes V, Whyman A, Currell A, Bernard S, Walker T, et al. A model of survival following pre-hospital cardiac arrest based on the Victorian Ambulance Cardiac Arrest Register. Resuscitation. 2007;75(2):311-22.

28. Hollenberg J, Herlitz J, Lindqvist J, Riva G, Bohm K, Rosenqvist M, et al. Improved survival after out-of-hospital cardiac arrest is associated with an increase in proportion of emergency crew-witnessed cases and bystander cardiopulmonary resuscitation. Circulation. 2008;118(4):389-96.

29. Reynolds JC, Frisch A, Rittenberger JC, Callaway CW. Duration of resuscitation efforts and functional outcome after out-of-hospital cardiac arrest: when should we change to novel therapies? Circulation. 2013; 128(23):2488-94

30. Lin S, Callaway CW, Shah PS, Wagner JD, Beyene J, Ziegler CP, et al. Adrenaline for out-of-hospital cardiac arrest resuscitation: a systematic review and meta-analysis of randomized controlled trials. Resuscitation. 2014;85(6):732-40.

31. Hagihara A, Hasegawa M, Abe T, Nagata T, Wakata Y, Miyazaki S. Prehospital epinephrine use and survival among patients with out-of-hospital cardiac arrest. JAMA. 2012;307(11):1161-8.

32. Rossetti AO, Oddo M, Logroscino G, Kaplan PW. Prognostication after cardiac arrest and hypothermia: a prospective study. Ann Neurol. 2010; 67(3):301-7.

33. Fugate JE, Wijdicks EF, Mandrekar J, Claassen DO, Manno EM, White RD, et al. Predictors of neurologic outcome in hypothermia after cardiac arrest. Ann Neurol. 2010;68(6):907-14
34. Trzeciak S, Jones AE, Kilgannon JH, Milcarek B, Hunter K, Shapiro NI, et al. Significance of arterial hypotension after resuscitation from cardiac arrest. Crit Care Med. 2009;37(11):2895-903.

35. Lemiale V, Dumas F, Mongardon N, Giovanetti O, Charpentier J, Chiche JD, et al. Intensive care unit mortality after cardiac arrest: the relative contribution of shock and brain injury in a large cohort. Intensive Care Med. 2013;39(11):1972-80.

36. Sasson C, Rogers MAM, Dahl J, Kellermann AL. Predictors of survival from out-of-hospital cardiac arrest a systematic review and meta-analysis. Circ Cardiovasc Qual Outcomes. 2010;3(1):63-81.

37. Bisbal M, Jouve E, Papazian L, de Bourmont S, Perrin G, Eon B, et al. Effectiveness of SAPS III to predict hospital mortality for post-cardiac arrest patients. Resuscitation. 2014;85(7):939-44.

38. Soar J, Nolan JP, Böttiger BW, Perkins GD, Lott C, Carli P, et al. European Resuscitation Council Guidelines for Resuscitation 2015: Section 3. Adult advanced life support. Resuscitation. 2015;95:100-47.

39. Winther-Jensen M, Kjaergaard J, Nielsen N, Kuiper M, Friberg H, Søholm H, et al. Comorbidity burden is not associated with higher mortality after outof-hospital cardiac arrest. Scand Cardiovasc J. 2016;50:305-10.

40. Knaus WA, Draper EA, Wagner DP, Zimmerman JE. APACHE II: a severity of disease classification system. Crit Care Med. 1985;13(10):818-29.

41. Niskanen M, Kari A, Nikki $P$, lisalo E, Kaukinen L, Rauhala V, et al. Acute Physiology and Chronic Health Evaluation (APACHE II) and Glasgow Coma Scores as predictors of outcome from intensive care after cardiac arrest. Crit Care Med. 1991;19(12):1465-73.

42. Jabre $P$, Bougouin W, Dumas F, Carli P, Antoine C, Jacob L, et al. Early identification of patients with out-of-hospital cardiac arrest with no chance of survival and consideration for organ donation. Ann Intern Med. 2016; 165(11):770-8.

\section{Submit your next manuscript to BioMed Central and we will help you at every step:}

- We accept pre-submission inquiries

- Our selector tool helps you to find the most relevant journal

- We provide round the clock customer support

- Convenient online submission

- Thorough peer review

- Inclusion in PubMed and all major indexing services

- Maximum visibility for your research

Submit your manuscript at www.biomedcentral.com/submit
C) Biomed Central 